\title{
Effect of Form-focused Pragmatic Instruction on Production of Conventional Expressions
}

\author{
Vahid Rafieyan \\ School of Educational Studies, Univesiti Sains Malaysia, Penang, Malaysia \\ Maryam Sharafi-Nejad \\ School of Educational Studies, Univesiti Sains Malaysia, Penang, Malaysia \\ Lin Siew Eng \\ School of Educational Studies, Univesiti Sains Malaysia, Penang, Malaysia
}

\begin{abstract}
Knowledge of target language conventional expressions is of crucial importance for language learners not only because they contribute to nativelike speech fluency but also because speakers from the same speech community share knowledge and use of the same inventory of conventional expressions. To assess the effect of form-focused pragmatic instruction in general and the effect of type of form-focused pragmatic instruction including Focus on Form and Focus on Forms methods in particular on improving the ability to produce target language conventional expressions appropriately, an experimental study was conducted over 45 senior undergraduate learners of English as a Foreign Language at a university in Iran. The experiment comprised random assignment of participants into three groups consisting of two experimental groups (Focus on Form group and Focus on Forms group) and one control group, conducting eight intervention sessions, and administration of a discourse completion task. The findings revealed that generally form-focused pragmatic instruction was effective in improving the ability to produce target language conventional expressions appropriately and there was no significant difference between the effect of Focus on Form and Focus on Forms pragmatic instruction. The pedagogical implications of the findings suggested furnishing foreign language classrooms with form-focused pragmatic instruction.
\end{abstract}

Index Terms - conventional expressions, form-focused instruction, input flood, metapragmatic explanation

\section{INTRODUCTION}

Conventional expressions, described as "tacit agreements, which the members of a community presume to be shared by every reasonable co-member" (Coulmas, 1981, p. 4), "consist of strings such as no problem, nice to meet you, and that'd be great, which native speakers use predictable in certain contexts" (Bardovi-Harlig, 2009, p. 756). Knowledge of target language conventional expressions for language learners is of crucial importance not only because they contribute to nativelike speech fluency (Pawley \& Syder, 1983) but also because speakers from the same speech community share knowledge and use of the same inventory of conventional expressions (Wray, 2002), in other words, "in embodying societal knowledge they are essential in handling of day-to-day situations" (Coulmas, 1981, p. 4).

However, "In spite of their communicative value, conventional expressions are not acquired seamlessly even by advanced language learners" (Bardovi-Harlig \& Vellenga, 2012, p. 77). In fact, language learners cannot necessarily handle social situations in the same way as native speakers because they do not have ready access to, and therefore do not make use of, conventionalized expressions in the target language for meeting the social imposition as native speakers do (Edmondson \& House, 1991). Clearly, the best way to acquire target language conventional expressions is to experience language immersion in the target language community (Roever, 2012), but not all language learners in a foreign language context have the opportunity to do so (Lin, 2014).

Therefore, inclusion of conventional expressions in foreign language classroom instruction can provide some virtual language immersion in a target language community for foreign language learners. The instruction can be presented in various methods including implicit Focus on Form methods of instruction and explicit Focus on Forms methods of instruction. However, there is no consensus on the ideal method of teaching target language pragmatics in foreign language classrooms. While some studies found the positive effect of Focus on Form pragmatic instruction (e.g. Ulbegi, 2009; Khatib \& Safari, 2013), some others found Focus on Forms pragmatic instruction useful in developing target language pragmatic competence in foreign language learners (e.g. Ghobadi \& Fahim, 2009; Lingli \& Wannaruk, 2010; $\mathrm{Bu}, 2012$; Nguyen et al., 2012).

To this end, the current study adopted an experimental research methodology by conducting both Focus on Form and Focus on Forms pragmatic instruction on learners of English as a Foreign Language to assess the effect of pragmatic instruction on the acquisition of target language conventional expressions in general and to determine the ideal method 
of teaching target language conventional expressions in particular. More specifically, the research questions to be addressed in the current study are:

1. Does form-focused pragmatic instruction improve the ability to produce target language conventional expressions?

2. Which type of form-focused pragmatic instruction (Focus on Form or Focus on Forms) is more effective in improving the ability to produce target language conventional expressions?

Accordingly the null hypotheses are:

1. Form-focused pragmatic instruction has no significant effect in improving the ability to produce target language conventional expressions.

2. There is no significant difference between Focus on Form and Focus on Forms pragmatic instruction in improving the ability to produce target language conventional expressions.

\section{LITERATURE REVIEW}

Studies on conventional expressions conducted so far have been both cross-sectional and developmental. Some studies have explored the role of individual difference variables such as first language (e.g. Bardovi-Harlig et al., 2008), language proficiency (e.g. Bardovi-Harlig et al., 2008; Taguchi, 2013), study abroad experience (Taguchi, 2013), and pragmatic awareness (Bardovi-Harlig, 2014) on the production of conventional expressions. Some other studies also investigated the reasons for the low production of conventional expressions (Bardovi-Harlig, 2009) and the effect of instruction on the ability to produce conventional expressions (Bardovi-Harlig \& Vellenga, 2012). There is, however, a growing need to examine the ideal way of presenting target language conventional expressions in foreign language classrooms.

In one study, Bardovi-Harlig et al. (2008) investigated the influence of first language and level of instruction on the development and use of conventional expressions. Participants consisted of 108 language learners from distinct countries in four levels of classes, from low-intermediate to low-advanced, of an Intensive English Program at a university in the American Midwest. The study employed a speech production task via a computer-delivered aural discourse completion task. The findings showed that language learners of various native languages often share production strategies and language learners increase their use of conventional expressions at higher levels.

In another study, Bardovi-Harlig (2009) explored the source of low production of conventional expressions by language learners. Participants consisted of 122 learners of English enrolled in the Intensive English Program of a university in the American Midwest. The instruments consisted of an audio recognition task, an audio-visual production task, and a background questionnaire. The results suggested that low production of conventional expressions by language learners has multiple sources including lack of familiarity with some expressions, overuse of familiar expressions, level of development, and sociopragmatic knowledge.

Bardovi-Harlig and Vellenga (2012) conducted another study, using an experimental research design, to investigate the effect of instruction on the oral production of conventional expressions. Participants in the study consisted of 36 language learners in the Intensive English Program of a university in the American Midwest. An aural recognition task and an oral production task were used as pre-test and post-test. Intervention consisted of three sessions centered around contextualized input and guided metapragmatic noticing. The findings suggested that instruction promoted the use of some conventional expressions.

Taguchi (2013) also investigated the effect of general language proficiency and study abroad experience on appropriate and fluent production of target language conventional expressions. Participants in the study included three groups of Japanese learners of English at a university in Japan: a low language proficiency without study abroad experience group, a high language proficiency without study abroad experience group, and a high language proficiency with study abroad experience group. The ability to produce target language conventional expressions was assessed through a computerized oral discourse completion test. The findings suggested that while all learner groups failed to reach a native level, study abroad experience presented an advantage in the appropriate production of conventional expressions whereas proficiency presented an advantage in speech rates.

Most recently, Bardovi-Harlig (2014) investigated language learners' awareness of the meaning of target language conventional expressions and the effect of the associated meanings on the use of conventional expressions in social interactions. One hundred and fourteen language learners enrolled in the Intensive English Program of a university in the American Midwest participated in the study. To explore the meaning that language learners assigned to conventional expressions, the modified aural Vocabulary Knowledge Scale was used. The data suggested that language learners' awareness of the meaning of conventional expressions seems likely to play a role in whether language learners use an expression and which expression among related expressions they use to the exclusion of others.

\section{METHODOLOGY}

\section{A. Participants}

Participants in the study consisted of 45 undergraduate learners of English as a Foreign Language at the Islamic Azad University of Abadan in Iran. Among the participants, 15 were males and 30 were females. Their ages ranged from 22 to 28 with a mean age of 24.5 years old. These participants were considered suitable for the study as they were at the 
last year of their study and had not experienced visiting or living in a native English-speaking country. Therefore, not only they were supposed to possess a high level of linguistic competence but also they did not have the opportunity to develop pragmatic competence.

\section{B. Instrument}

The instrument used in the study was an oral discourse completion task eliciting a variety of speech acts including expressions of gratitude, apologies, warnings, leave-takings, requests, condolences, declining offers, acceptance of a request, acceptance of an invitation, invitation, declining an invitation, an agreement, deflecting thanks, and an introduction developed by Bardovi-Harlig (2009). The discourse completion task consisted of 32 scenarios comprising of both initiating and responding scenarios. The initiating scenarios $(n=13)$ required respondents to initiate an interaction and the responding scenarios $(n=19)$ required respondents to respond to an interlocutor's turn.

To assess the validity of the scenarios on the discourse completion task, content validity was assessed. Two lecturers who were experts in the field of interlanguage pragmatics judged and confirmed the appropriateness of scenarios for the study. To assess the reliability of the scenarios on the discourse completion task, a pilot study was conducted over 30 other undergraduate learners of English as a Foreign Language in the Islamic Azad University of Abadan who did not participate in the main study. The reliability coefficient assessed through Kurder Richardson 21 was 0.82.

\section{Procedure}

During the fall semester in the academic year 2013/2014, participants were randomly assigned to three groups of 15 each consisting of two experimental groups and one control group. Participants in one of the experimental groups received Focus on Form pragmatic instruction through watching videos and reading texts flooded by target language conventional expressions. Participants in the other experimental group received Focus on Forms pragmatic instruction through metapragmatic explanations of target language conventional expressions followed by role plays. Participants in the control group were merely taught the grammatical features of the target language. Intervention was held twice weekly for two sessions a week, comprising 8 sessions (each session lasting for 60 minutes) of instruction per group. Following the intervention, the oral discourse completion task was administered to all participants in the language laboratory of the university. Participants heard the scenarios through headphones and responded orally. The responses were recorded from their headphones onto a digital file for the data analysis.

\section{Data Analysis}

All responses were transcribed and checked by the researchers. The appropriateness of the responses was then assessed by two native speakers of English using a four-point rating scale ranging from zero (cannot evaluate) to three (almost perfect). Interrater reliability was $r=0.92$. Table I displays the rating descriptions. As there were 32 scenarios, each participant could get a mark ranging from 0 to 96 . The performance of participants in the three groups was then compared through independent-measures analysis of variance (ANOVA) to determine the effect of form-focused pragmatic instruction in general and the effect of type of pragmatic instruction in particular on the development of target language conventional expressions in language learners. Effect size was then calculated to determine the magnitude of the differences among mean scores, or the amount of the total variance in the dependent variable (i.e. production of target language conventional expressions) that is predicted from knowledge of the levels of the independent variable (i.e. type of pragmatic instruction) when the difference among mean scores is statistically significant.

TABLE I

RATING BAND DESCRIPTIONS

\begin{tabular}{|c|l|l|}
\hline 3 & Native-like & The utterance is almost perfectly appropriate. This is what a native speaker would usually say in the situation \\
\hline 2 & Slightly off, but acceptable & The utterance is a little off from native-like due to minor grammatical and lexical errors but overall acceptable \\
\hline 1 & Obviously off & $\begin{array}{l}\text { The utterance is clearly non-native like because of strange, non-typical way of saying and/or major } \\
\text { grammatical and lexical errors }\end{array}$ \\
\hline 0 & Can't evaluate & The utterance is impossible to understand \\
\hline \multicolumn{2}{|c}{ Adopted from Taguchi (2013) }
\end{tabular}

\section{FINDINGS AND DiSCUSSION}

\section{A. Findings}

Table II presents the results of the independent-measures analysis of variance (ANOVA) for the performance of language learners in the three groups on the discourse completion task. The main data to be considered in the table is the significance value ( $\mathrm{p}$ value). If the significance value is less than or equal to 0.05 ( $\mathrm{p} \leq 0.05$ ), there is a significant difference somewhere among the mean scores on the dependent variable for the three groups. However; if the significance value is more than 0.05 ( $p>0.05$ ), the difference among the mean scores on the dependent variable for the three groups is not considered significant (Gravetter \& Wallnau, 2013; Pallant, 2013). The overall significance value obtained through the independent-measures analysis of variance (ANOVA) for the performance of language learners in the three groups on the discourse completion task in the current study is 0.00 which is less than 0.05 , indicating a 
statistically significant difference among the mean scores on the ability to produce conventional expressions for the language learners in the three groups. However, significance value does not show which group is different from which other group. It only shows whether or not there is a significant difference among the groups being compared. Statistical significance of the difference between each pair of groups is provided through the results of the post-hoc tests.

TABLE II

ANALYSIS OF VARIANCE

\begin{tabular}{|l|l|l|l|l|l|}
\hline & Sum of Squares & df & Mean Square & F & Sig. \\
\hline Between Groups & 3283.511 & 2 & 1641.756 & 24.951 & 0.000 \\
\hline Within Groups & 2763.600 & 42 & 65.800 & & \\
\hline Total & 6047.111 & 44 & & & \\
\hline
\end{tabular}

Table III presents the results of the post-hoc tests. The post-hoc tests show exactly where the difference among the groups occurs (Gravetter \& Wallnau, 2013; Pallant, 2013). There are a number of different post-hoc tests that can be used. The current study used Tukey's Honestly Significant Difference (HSD) test which is the most commonly used post-hoc test for the independent-measures analysis of variance (ANOVA). The asterisk (*) next to the values mean that the mean scores obtained by the two groups being compared are significantly different from one another. According to the results of the Tukey's test presented in the table, the mean score obtained through the performance of language learners in the control group on the discourse completion task used in the current study is statistically significantly different from the mean scores obtained through the performance of language learners in both Focus on Form group and Focus on Forms group (experimental groups) on the test. However, there is no statistically significant difference between the mean scores obtained through the performance of language learners in Focus on Form group and Focus on Forms group.

TABLE III

MULTIPLE COMPARISONS

\begin{tabular}{|c|c|c|c|c|c|c|}
\hline \multirow{2}{*}{ (I) Groups } & \multirow{2}{*}{ (J) Groups } & \multirow{2}{*}{$\begin{array}{l}\text { Mean Difference } \\
(\mathrm{I}-\mathrm{J})\end{array}$} & \multirow{2}{*}{ Std. Error } & \multirow{2}{*}{ Sig. } & \multicolumn{2}{|c|}{$95 \%$ Confidence Interval } \\
\hline & & & & & Lower Bound & Upper Bound \\
\hline \multirow{2}{*}{ Control Group } & Focus on Form Group & $-20.133 *$ & 2.962 & 0.000 & -27.33 & -12.94 \\
\hline & Focus on Forms Group & $-15.000 *$ & 2.962 & 0.003 & -22.20 & -7.80 \\
\hline Focus on Form Group & Focus on Forms Group & 5.133 & 2.962 & 0.205 & -2.06 & 12.33 \\
\hline \multirow{2}{*}{ Focus on Forms Group } & Control Group & $15.000 *$ & 2.962 & 0.000 & 7.80 & 22.20 \\
\hline & Focus on Form Group & -5.133 & 2.962 & 0.205 & -12.33 & 2.06 \\
\hline
\end{tabular}

*. The mean difference is significant at the 0.05 level.

Figure 1 depicts the comparison of the mean scores for the three groups of language learners participating in the current study. The mean scores obtained by the language learners in control group, Focus on Form group, and Focus on Forms group are respectively 48.73, 68.87, and 63.73. The figure shows that language learners in both experimental groups (Focus on Form group and Focus on Forms group) outperformed language learners in control group on the discourse completion task used in the current study. The comparison of the mean scores obtained by the language learners in the experimental groups also shows that although language learners in Focus on Form group had better performance in producing target language conventional expressions than language learners in Focus on Forms group, the difference is not considered statistically significant.

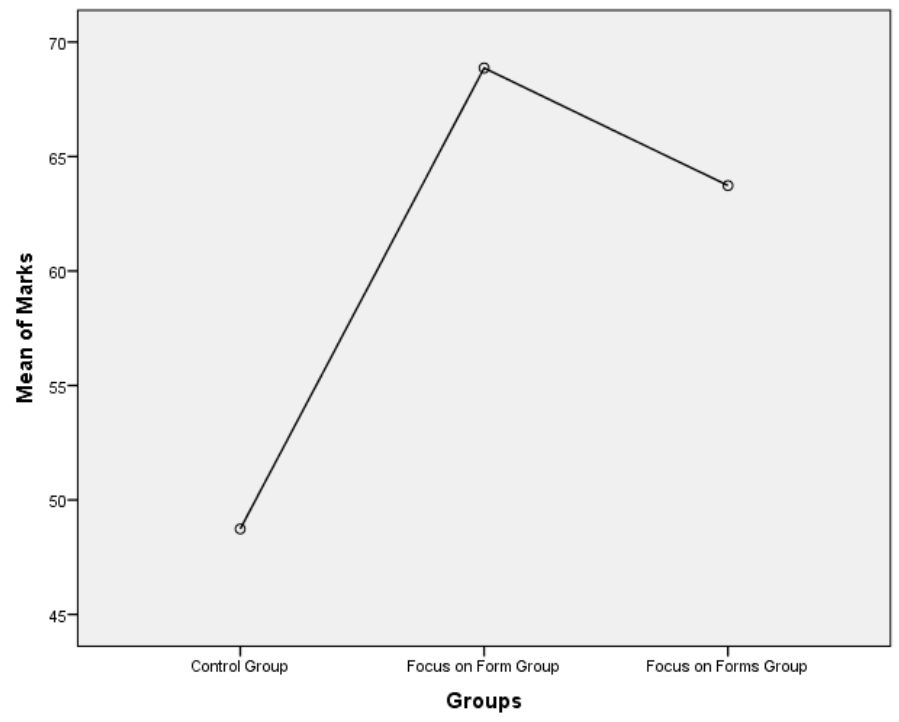

Figure 1. Performance of language learners in the three groups 
To determine the magnitude of the differences among mean scores, or the amount of the total variance in the dependent variable that is predicted from knowledge of the levels of the independent variable when the difference among mean scores is statistically significant, effect size needs to be calculated. The most commonly used measure of effect size with independent-measures analysis of variance (ANOVA) is eta squared ( $\left.n^{2}\right)$ which indicates the proportion of variance of the dependent variable that is explained by the independent variable. The formula to calculate eta squared is: "eta squared = sum of squares between groups / total sum of squares" (Gravetter \& Wallnau, 2013; Pallant, 2013). The measure of effect size computed through eta squared for the current study is 0.41 which according to the guidelines set by Cohen (1988) (i.e. 0.1 or $1 \%=$ small, 0.6 or $6 \%=$ medium, 0.24 or $14 \%=$ large) indicates a very large difference among mean scores obtained by the three different treatment groups. In other words, 41 percent of variance of the language learners' performance on the test is explained by the type of instruction.

\section{B. Discussion}

The current study explored the effect of form-focused pragmatic instruction in general as well as the effect of types of form-focused pragmatic instruction consisting of Focus on Form pragmatic instruction and Focus on Forms pragmatic instruction in particular on language learners' production of target language conventional expressions. The findings suggested that form-focused pragmatic instruction in general is conductive to promote the production of target language conventional expressions to a great extent. However, there is no significant difference between the effects of specific types of form-focused pragmatic instruction in this respect.

In the current study, language learners in the experimental groups who received pragmatic instruction, regardless of type of instruction, either using input flood through Focus on Form instruction or using metapragmatic explanations of target language conventional expressions through Focus on Forms instruction exhibited a significantly better performance on the production of target language conventional expressions than language learners in the control group who did not receive pragmatic instruction. However, the performance of language learners in both experimental groups did not show a marked difference from each other, that is, both Focus on Form and Focus on Forms pragmatic instruction relatively equally contributed to the language learners' knowledge of target language conventional expressions.

These findings can be explained through the noticing hypothesis proposed by Schmidt $(1990,2001)$ which states that "people learn about the things that they attend to and do not learn much about the things they do not attend to" (Schmidt, 2001, p. 30). Form-focused pragmatic instruction in the current study, regardless of the type (either in the form of Focus on Form or in the form of Focus on Forms), developed awareness of the differences between expressions which have been conventionalized in language learners' native language and expressions which have been conventionalized in the target language. The awareness of pragmatic differences between language learners' native language and target language conventional expressions most probably contributed to their noticing of the target language conventional expressions both inside classroom through the input they received and outside classroom through watching target language movies and reading target language books. Consequently, knowledge of target language conventional expressions was developed in them. Therefore, language learners in the experimental groups tended to use expressions which have been conventionalized in the target language rather than those which have been conventionalized in their native language in initiating and responding to the scenarios used in the current study to be sounded nativelike.

However, language learners in the control group did not receive awareness raising instruction about pragmatic differences between expressions which have been conventionalized in their native language and expressions which have been conventionalized in the target language to help them notice target language conventional expressions. Consequently, they relied on their knowledge of their native language conventional expressions in initiating and responding to the scenarios on the discourse completion task used in the current study as knowledge of target language conventional expressions did not develop in them.

These findings reject the first null hypothesis which states form-focused pragmatic instruction has no significant effect in improving the ability to produce target language conventional expressions. These findings, however, confirm the second null hypothesis which states there is no significant difference between Focus on Form and Focus on Forms pragmatic instruction in improving the ability to produce target language conventional expressions. The findings obtained in the current study are consistent with the findings obtained by Bardovi-Harlig and Vellenga (2012) who found that pragmatic instruction promotes the use of some target language conventional expressions.

\section{CONCLUSION}

The study found that form-focused pragmatic instruction was conductive to the development of knowledge of target language conventional expressions in language learners to a great extent. However, there was no significant difference between the various methods of presenting pragmatic instruction. Language learners in the experimental groups (Focus on Form group and Focus on Forms group) who received pragmatic instruction were more successful in appropriate production of target language conventional expressions than language learners in the control group who did not receive pragmatic instruction. However, there was no marked difference in the ability to produce target language conventional expressions between language learners in Focus on Form group and language learners in Focus on Forms group. These findings suggest that foreign language classrooms should be furnished with form-focused pragmatic instruction 
comparing language learners' native language conventional expressions with those used by target language speakers to help them to be sounded nativelike (Rafieyan et al., 2014; Rafieyan et al., in press).

\section{ACKNOWLEDGMENT}

The authors wish to thank Mohammad Rafieyan who inspired the research idea.

\section{REFERENCES}

[1] Bardovi-Harlig, K., Rose, M., Nickels, E. L. (2008). The Use of Conventional Expressions of Thanking, Apologizing, and Refusing (Selected Proceedings of the 2007 Second Language Research Forum, ed. Melissa Bowles et al., 113-130). Somerville, MA: Cascadilla Proceedings.

[2] Bardovi-Harlig, K. (2009). Conventional Expressions as a Pragmalinguistic Resource: Recognition and Production of Conventional Expressions in L2 Pragmatics. Language Learning, 59(4), 755-795. http://dx.doi.org/10.1111/j.14679922.2009.00525.x.

[3] Bardovi-Harlig, K. (2014). Awareness of Meaning of Conventional Expressions in Second-Language Pragmatics. Language Awareness, 23(1-2), 41-56. http://dx.doi.org/10.1080/09658416.2013.863894.

[4] Bardovi-Harlig, K., \& Vellenga, H. E. (2012). The Effect of Instruction on Conventional Expressions in L2 Pragmatics. System, 40(1), 77-89. http://dx.doi.org/10.1016/j.system.2012.01.004.

[5] Bu, J. (2012). A Study of the Effects of Explicit and Implicit Teachings on Developing Chinese EFL Learners' Pragmatic Competence. International Journal of Language Studies, 6(3), 57-80.

[6] Cohen, J. A. (1988). Statistical Power Analysis for the Behavioral Sciences. Hillsdale, NJ: Lawrence Erlbaum Associates.

[7] Coulmas, F. (1981). Conversational Routine: Explorations in Standardized Communication Situations and Prepatterned Speech. The Hague: Mouton.

[8] Edmondson, W., \& House, J. (1991). Do Learners Talk Too Much? The Waffle Phenomenon in Interlanguage Pragmatics. In R. Phillipson, E. Kellerman, L. Selinker, M. Sharwood Smith, \& M. Swain (Eds.), Foreign/Second Language Pedagogy Research: A Commemorative Volume for Claus Faerch (pp. 273-287). Clevedon, UK: Multilingual Matters.

[9] Ghobadi, A., \& Fahim, M. (2009). The Effect of Explicit Teaching of English "Thanking Formulas" on Iranian EFL Intermediate Level Students at English Language Institutes. System, 37(3), 526-537. http://dx.doi.org/10.1016/j.system.2009.02.010.

[10] Gravetter, F. J., \& Wallnau, L. B. (2013). Statistics for the Behavioral Sciences. Belmont, CA: Wadsworth Publishing.

[11] Lin, P. M. S. (2014). Investigating the Validity of Internet Television as a Resource for Acquiring L2 Formulaic Sequences. System, 42(1), 164-176. http://dx.doi.org/10.1016/j.system.2013.11.010.

[12] Khatib, M., \& Safari, M. (2013). Does Input Enhancement Work for Learning Politeness Strategies? English Language Teaching, 6(12), 136-143. http://dx.doi.org/10.5539/elt.v6n12p136.

[13] Lingli, D., \& Wannaruk, A. (2010). The Effects of Explicit and Implicit Instruction in English Refusals. Chinese Journal of Applied Linguistics, 33(3), 93-109.

[14] Nguyen, T. T. M., Pham, T. H., \& Pham, M. T. (2012). The Relative Effects of Explicit and Implicit Form-Focused Instruction on the Development of L2 Pragmatic Competence. Journal of Pragmatics, 44(4), 416-434. http://dx.doi.org/10.1016/j.pragma.2012.01.003.

[15] Pallant, J. (2013). SPSS Survival Manual: A Step by Step Guide to Data Analysis Using SPSS Program (5th ed.). Australia: Allen \& Unwin.

[16] Pawley, A., \& Syder, H. (1983). Two Puzzles for Linguistic Theory: Native-Like Selection and Native-Like Fluency. In J. Richards, \& R. Schmidt, (Eds.), Language and Communication (pp. 191-226). London: Longman.

[17] Rafieyan, V., Sharafi-Nejad, M., \& Lin, S. E. (2014). Effect of Pragmatic Instruction on Sustainable Development of Pragmatic Awareness. Journal of Studies in Education, 4(1), 206-218. http://dx.doi.org/10.5296/jse.v4i1.5088.

[18] Rafieyan, V., Sharafi-Nejad, M., Damavand, A., Lin, S. E., \& Abdul-Rashid, M. (in press). Relationship between Emotional Intelligence and Pragmatic Awareness. International Journal of Applied Linguistics \& English Literature, 3(4).

[19] Roever, C. (2012). What Learners Get for Free: Learning of Routine Formulae in ESL and EFL Environments. ELT Journal, 66(1), 10-21. http://dx.doi.org/10.1093/elt/ccq090.

[20] Schmidt, R. W. (1990). The Role of Consciousness in Second Language Learning. Applied Linguistics, 11(2), 129-158. http://dx.doi.org/10.1093/applin/11.2.129.

[21] Schmidt, R. W. (2001). Attention. In P. Robinson (Ed.), Cognition and Second Language Instruction (pp. 3-32). Cambridge: Cambridge University Press. http://dx.doi.org/10.1017/CBO9781139524780.003.

[22] Taguchi, N. (2013). Production of Routines in L2 English: Effect of Proficiency and Study-Abroad Experience. System, 4l(1), 109-121. http://dx.doi.org/10.1016/j.system.2013.01.003.

[23] Ulbegi, E. (2009). The Effects of Implicit vs. Explicit Instruction on Pragmatic Development: Teaching Polite Refusals in English. Egitim Fakultesi Dergisi, 22(2), 327-356.

[24] Wray, A. (2002). Formulaic Language and the Lexicon. Cambridge: Cambridge University Press. 


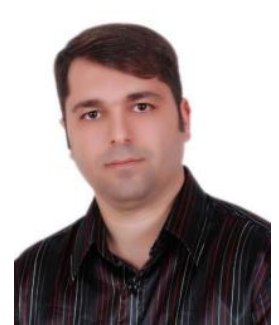

Vahid Rafieyan is currently a $\mathrm{PhD}$ candidate at the school of educational studies in Universiti Sains Malaysia (USM). He has eleven years of experience teaching IELTS, communicative language, and academic writing. $\mathrm{He}$ has a number of publications in the field of interlanguage pragmatics including "relationship between attitude toward target language culture instruction and pragmatic comprehension development", "relationship between cultural distance and pragmatic comprehension", and "pragmatic comprehension development through telecollaboration". He holds the 2012 best TESL student award from Universiti Teknologi Malaysia (UTM).

Maryam Sharafi-Nejad is currently a PhD candidate at the School of Educational Studies in Universiti Sains Malaysia (USM). She has five years of experience teaching IELTS and academic writing. She has a number of publications in the field of interlanguage pragmatics including "effect of pragmatic instruction on sustainable development of pragmatic awareness", "pragmatic comprehension development through telecollaboration", and "relationship between cultural distance and pragmatic comprehension".

Lin Siew Eng, PhD is currently the Programme Chairperson (Bachelor of Education -TESOL at the School of Educational Studies, Universiti Sains Malaysia. Her areas of specialisation are Teaching of English as a Second Language and Reading. Her areas of research are Benchmarking English Language Reading Abilities, Reading Matrix Development and Benchmarking English Language Grammar Proficiency. She has won awards in the innovation of 'Reading Evaluation And Decoding System' and 'Grammar Assessment and Management System'. 